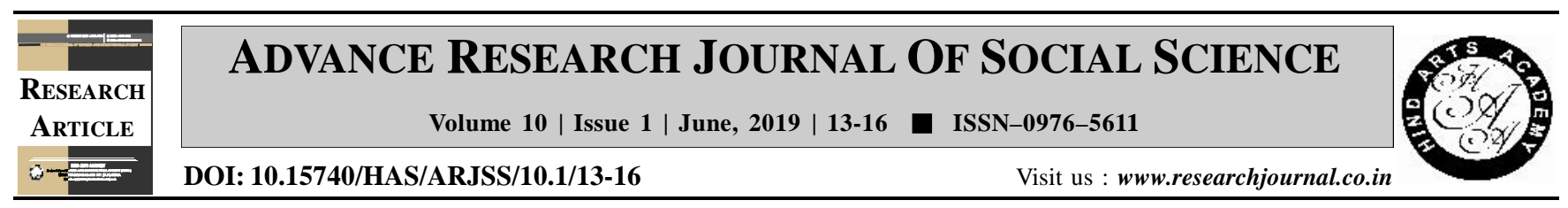

\title{
Dietary pattern of adolescence girls of urban, rural and slum areas in Kanpur district
}

Nidhee Sachan* and Mile Lata

Department of Food Science and Nutrition, Jiwaji University, Gwalior (M.P.) India

(Email : nidheesachan3@gmail.com)

\section{ARTICLE INFO :}

$\begin{array}{lll}\text { Received } & : & 11.03 .2019 \\ \text { Revised } & : & 04.05 .2019 \\ \text { Accepted } & : & 15.05 .2019\end{array}$

\section{KEY WORDS :}

Adolescent girls, Dietary pattern, Iron deficiency, Nutritional status, Nutritional awareness, Environmental hygiene

\section{HOW TO CITE THIS ARTICLE :}

Sachan, Nidhee and Lata, Mile (2019). Dietary pattern of adolescence girls of urban, rural and slum areas in Kanpur district. Adv. Res. J. Soc. Sci., 10 (1) : 1316, DOI: 10.15740/HAS/ARJSS/10.1/ 13-16. Copyright@2019 : Hind Agri Horticultural Society

*Author for correspondence

\begin{abstract}
Adolescent may represent a window of opportunity to prepare nutritionally for a healthy adult life. Adolescence is an important stage of growth and development in the lifespan. Unique nutritional and health needs of the adolescents are also more important because of more requirements for growth spurt and increase in physical activity. It also supports other bodily functions such as growth, maintenance and repair.The objective of the study was to determine the nutritional status of adolescent girls and to study the relationship between the socio-economic statuses of the respondents with dietary habit of adolescent girls in urban, rural and slum areas in Kanpur district. A study was carried out amongst adolescent girls in the age group of 14-18 years. Urban, rural and slum areas of Kanpur district were selected for study purpose and study period was from January to June 2016.Total 150 adolescent girls were included. The 72.0 per cent, 88.0 per cent and 84.0 per cent girls in urban, rural and slum areas were belonged to 14-16 age groups. Majority of urban girls were educated. The very poor eating habits and life style conditions were found in slum areas. But, its conditions were better in rural than slum. Most of girls' vegetarian in rural area. Urban girls more nutritional awareness compared were rural and slum areas. The urban girls were more physically better than rural and slum areas. The socio-economic conditions of urban area correspondents were better than rural and slum areas. Nutritional status has profound effect on health and food consumption performance of adolescent girls. The health of the adolescent girls is closely related to nutritional status but there are certain other eco-social variables such as literacy, social status and environmental hygiene which have impact on health of the girls.
\end{abstract}

